\section{Unmixing of hot inorganic melts}

SIR - Phase separation with decreasing temperature occurs in silicate, phosphate and borate liquids and glasses. Phase separation with increasing temperature (a lower critical solution temperature, LCST) is known in various organic systems but has neither been proposed nor documented for oxide liquids. I suggest that an LCST is possible in oxides, present thermodynamic arguments based on the breakdown of complex species with increasing temperature, and summarize circumstantial evidence consistent with an LCST.

The figure $(a)$ shows immiscibility with decreasing temperature in a silicate. The stabilizing contribution of the entropy of mixing $(T \Delta S)$, which increases with increasing temperature, overpowers the destabilizing energetics (positive $\Delta \mathrm{H}$ ), causing the miscibility gap to close. This is not the only topology for phase separation. An LCST is known in various organic molecular and polymeric systems $(b$ in the figure). A closed loop of immiscibility $(c)$ or an 'hourglass' shape $(d)$ have been seen.

Immiscibility which increases with increasing temperature can be explained on thermodynamic grounds. In a system $\mathrm{A}-\mathrm{B}$, the energy of interaction between $A$ and $\mathrm{B}$ is positive (destabilizing) if $A$ and $B$ differ significantly in size and bonding requirements. However, if $\mathrm{A}$ and $\mathrm{B}$ form a complex or bond strongly, their interaction is negative (stabilizing). Such complexes, though, energetically favourable, represent a melt structuring which lowers its entropy. Therefore complexes tend to dissociate on heating. If $\mathrm{A}-\mathrm{B}$ interactions are unfavourable, immiscibility may set in as the concentrations of free $\mathrm{A}$ and $\mathrm{B}$ increase. If $\mathrm{A}-\mathrm{B}$ interactions are only moderately unfavourable, this miscibility gap may close again at high temperature.

Can a similar mechanism apply to silicates, borates and phosphates? Phaseequilibrium studies have not reported an LCST. However, it may not be easy to observe an LCST. Because phase separation occurs at high temperature, where both diffusion and speciation changes are rapid, the phase-separated regime might be difficult to quench and observe. Once a homogeneous liquid is detected above the liquidus, few people have continued heating that liquid several hundred degrees higher to see if it

unmixes. If an LCST is not considered, people may attribute seemingly inconsistent observations to experimental problems, or simply not publish them. Several investigators have brought to my attention unpublished data for borates and phosphates, which do not fit the expected picture of immiscibility and which could suggest an LCST. The most concrete example occurs in $\mathrm{La}_{2} \mathrm{O}_{3}-\mathrm{B}_{2} \mathrm{O}_{3}$. Working with large pots of glass melt, Malmendier ${ }^{1}$ noted that lanthanum-rich glasses could be formed only by slow
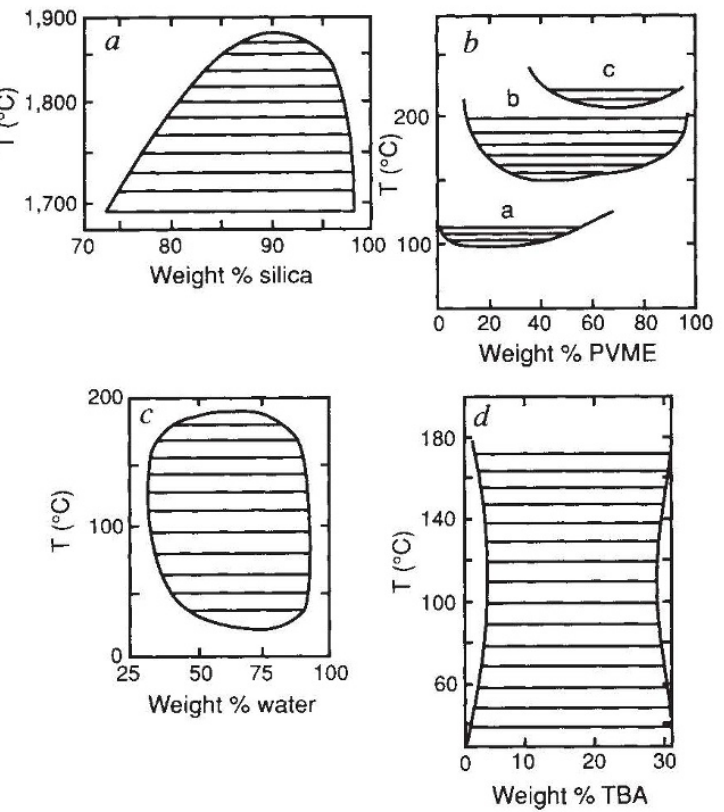

Some experimentally observed topologies for immiscibility. , UCST in the system $\mathrm{CaO}-\mathrm{SiO}_{2}$ (ref. 7); $b$, LCST in polystyrene (PS)--polyvinyl methylether (PVME) (ref. 8), a, tyrene monomer; b, relative molecular mass 110,000 monodisperse polystyrene (PS); c, $M_{\mathrm{r}} 200,000$ PS; $c$, both UCST and LCST in 2,4dimethylpyridine--water ${ }^{9}$; $d$, hourglass olvus in $M_{\mathrm{r}} 7190$ polyethylene glycol-t-butyl acetate $(\mathrm{TBA})^{10}$.

cooling, rapid cooling resulting in phase separation and/or crystallization. Malmendier did not investigate this in detail, but suggested that crystallization was influenced by temperature-induced changes in boron coordination. An LCST, with a two-phase liquid at higher temperature quenching to two glasses, one of which crystallizes rapidly, is another plausible explanation.

Complexes, especially between alkalis and large polyvalent cations, have been inferred from phase equilibria, thermochemistry, vibrational spectroscopy and $\mathrm{NMR}^{2}$. Can they dissociate with increasing temperature to cause an LCST? The evidence is indirect. A change in speciation is expected to cause a stronger than normal change in physical properties with temperature. Heat capacity measurements for $\mathrm{K}_{2} \mathrm{O} \cdot 2 \mathrm{SiO}_{2}$ compared to $\mathrm{K}_{2} \mathrm{O} \cdot \mathrm{TiO}_{2} \cdot \mathrm{SiO}_{2}$ and $\mathrm{K}_{2} \mathrm{O} \cdot 3 \mathrm{SiO}_{2}$ compared to $\mathrm{K}_{2} \mathrm{O} \cdot \mathrm{TiO}_{2} \cdot 2 \mathrm{SiO}_{2}$ show such an anomaly ${ }^{3}$. The heat capacities of the titanate and silicate liquids at very high temperature are similar, but the melts in which one mole of $\mathrm{SiO}_{2}$ is replaced by $\mathrm{TiO}_{2}$ show a much larger heat capacity in the first two hundred degrees above the glass transition, not seen for the titanium-free systems. This may reflect change in $\mathrm{Ti}$ coordination and/or dissociation of potassium titanate complexes.

Non-arrhenian viscosity in oxide glasses and melts ${ }^{2}$ is consistent with significant change in structure with temperature. Liquids classified as 'fragile' by Angell ${ }^{4}$ represent systems whose structures change sharply with increasing temperature to states of higher energy and higher entropy, consistent with the breakdown of complexes. Negative heats of mixing in $(\mathrm{Na}, \mathrm{K})$ aluminosilicate glasses ${ }^{5}$, which appear to be absent in the melts ${ }^{6}$, also suggest temperature-induced dissociation. Thus the stage is set for temperature-induced unmixing if the dissociated species interact unfavourably.

An LCST in oxide melts would have significant implications for ceramic processing and magma evolution. Modern in situ hightemperature spectroscopy and careful phase studies of systems well above their liquidus temperatures could test this hypothesis. Candidate ceramic systems might be borates, phosphates or silicates containing rare earths or alkalis and $\mathrm{Nb}, \mathrm{Mo}, \mathrm{Zr}$ or $\mathrm{Ti}$, as well as fluorides and fluorozirconates. Geological melts should be relatively depolymerized and contain significant concentrations of alkalis and large polyvalent cations. Komatiitic liquids meet the first but not the second criterion. Pressure and water content may affect LCST behaviour in magmas. All these predictions are necessarily tentative: an LCST may show up quite unexpectedly.

\section{Alexandra Navrotsky}

Department of Geological and

Geophysical Sciences,

Princeton University,

Princeton,

New Jersey 08544, USA

1. Malmendier, W. J. thesis (Penn State Univ., 1969).

2. Scarfe, C. M. (ed) Short Course in Silicate Melts (Min Ass. Canada, Toronto, 1986).

3. Lange, R. A. \& Naviotsky, A. Eos 71, 1650 (1990).

4. Angell, C. A. in Relaxation in Complex Systems (eds Ngai, K. \& Wright, G. B.) 1-10 (U.S. Dept. Commerce Springfieid, 1985)

5. Hervig, R. L. \& Navrotsky, A. Geochim. cosmochim. Acta 48, 513-522 (1984).

6. Rammensee, W. \& Fraser, D. G. Geochim cosmochim Acta 46, 2269-2279 (1982)

Tewhey, J. D. \& Hess, P. C. Phys, chem, Glasses 20 41-53 (1979).

8. Nishi, T. \& Kwei, T. K. Polymer 18, 285-290 (1975)

9. Oonk, H. A. J. Phase Theory - The Thermodynamics of Heterogeneous Equilibria (Elsevier, Amsterdam, 1981)

10. Saeki, S., Kuwahara, N., Nakata, M. \& Kaneko, M. Polymer 17, 685-689 (1976) 